\title{
Analysis on Teaching Methods of Industrial and Commercial Management Based on Knowledge Transform Expansion Model of "SECI"
}

\author{
Jing Yang ${ }^{\mathrm{a}, \mathrm{b}, * 1}$, Yingwen $\operatorname{Pan}^{\mathrm{b}, * 2}$ \\ ${ }^{a}$ School of Business Administration, Xi'an University of Technology, Xi'an, China \\ ${ }^{b}$ Management School, Xi'an Polytechnic University, Xi'an, China
}

\begin{abstract}
According to the characteristic of Industrial and commercial Management specialty, especially "stronger practice", in order to promote the transform of professional knowledge between explicit knowledge and tacit knowledge, the expansion model of SECI is introduced into the explorative analysis, and corresponding teaching methods and models are raised to facilitate the mastery and flexible application of students' professional knowledge.
\end{abstract}

Index Terms: The Model of SECI; Industrial and Commercial Management Major; Teaching

(C) 2011 Published by MECS Publisher. Selection and/or peer review under responsibility of the International Conference on E-Business System and Education Technology

\section{Introduction}

Bachelor of Industrial and Commercial Management graduates will be engaged in management and science in enterprises and government institutions. Thus the specialty requires undergraduate students with a wide range of knowledge and ability, with high professionalism and ability to solve problems related to practices. So undergraduate education of Industrial and Commercial Management must pay close attention to market demand. While the biggest difference between Industrial and Commercial Management with other majors is characteristics of "strong practical" and "soft". This requires that students not only to master the professional knowledge and expertise should also be able to use flexible. To enable students to better grasp and flexibility in the use of the knowledge, This paper will use the theory of knowledge transfer- the classic SECI model, proposed by Nonaka and so on, combining the characteristics of Industrial and Commercial Management, to put forward suggestions about teaching methods to promote professional students control and use expertise flexible. 


\section{Subject Characteristics of Industrial and Commercial Management}

From the professional development programs of Industrial and Commercial Management in every University, educational goals of this major are to develop senior specialists with knowledge and skills about administrative, economic, legal and corporate management, who can be engaged in business management, management consulting and the professional teaching and research work in enterprises, institutions and government departments. The professional training of students must have the capability of analyzing and solving business issues and strong innovation adapt to management needs.

Compared with other professional, Industrial and Commercial Management has different disciplines characteristics, and this makes different demands on teaching and training, mainly in the following areas:

\subsection{Strong Practicality}

The practice manifested in two aspects. First, many of the professional courses, theories (for example: "Principles of Management", "Human Resource Management", "Strategic Management") themselves from the objective management practices. Second, the Industrial and Commercial Management theory into practice, some achievements can be made by appropriately combining management theories and methods with individual and typical natural of practical management. Because of strong practicality undergraduate students can not learn from the learning effect immediately, only after a long working time they can learn that.

\subsection{WideRange of Applications}

Industrial and Commercial Management have a wide range of application. From training objectives and plans of Industrial and Commercial Management in every university, Employment of the major is geared to the needs of enterprises, institutions and government departments. And facing so many management theories, for undergraduates besides understanding and memorizing, it is more important to master a method of analyzing and solving problems through theoretical study. Therefore in the teaching process, besides teaching undergraduates the professional basic theories and knowledge, teaching emphasis should be placed on the cultivation of students' way of thinking and the sense of innovation.

\subsection{Marginality andComprehensiveness}

Many courses of Industrial and Commercial Management cover economics, philosophy, sociology, psychology and other branches of engineering and technical expertise [1].The characteristic of marginality and comprehensiveness determine that undergraduates of the major must have abroad professional foundation, relevant professional expertise, strong overall quality and ability.

\section{Tacit Knowledge and Explicit Knowledge}

Polanyi (1957) first distinguished two basic types of knowledge: explicit knowledge and tacit knowledge [2]. Explicit knowledge are those that have been formally documented and systematic (Encoded Knowledge). Such knowledge can easily be merged, extraction, storage and transfer, So Explicit knowledge are usually easy to record, usually in books or pictures. While tacit knowledge are those implicit in the human body and mind, are not easily coded and transmitted. The knowledge can be expressed only through Behavior of specific location and scene [3]. Tacit knowledge is often derived from experience, only through observation and imitation can be attained. Dissemination of tacit knowledge requires face to face through hands-on teaching and communication, and its transfer mostly depends upon exchange of personnel. 
Professional knowledge of the Industrial and Commercial Management is also divided into explicit knowledge and tacit knowledge. Because of characteristic of strong practicality, many principles of management theory are objective laws summarized from the management practices and finally become documented and expressed knowledge. Therefore principles of management theory, management procedures, methods, processes are explicit knowledge. For undergraduates it's easy to grasp the principles etc. above. While how to flexibly apply the principles etc. to practice is difficult. That is how to flexibly apply the learned principles etc. to practice is tacit knowledge.

Only after individuals or organizations hold tacit knowledge, the explicit knowledge will play a role, and in the vast majority of practice, explicit knowledge and tacit knowledge is always used one after. The process of cooking is a good example. Recipes only tell you how to prepare a meal, In order to successfully complete it must have some experience and understanding to apply the knowledge of the Recipes. The same applies to the management. For example, knowledge of Strategic Management course content is the explicit knowledge. But in practice undergraduates faced the contents of Strategic Management textbook may be at a loss, Because of lack of corresponding tacit knowledge, explicit knowledge will not be able to play the corresponding role. The "soft" is the characteristics of Industrial and Commercial Management. Obviously, mastery of tacit knowledge is difficult.

In teaching process, how can we enable students to have a good grasp of tacit knowledge, and what kind of teaching method can make the students flexible apply the expertise into practice, These require enhance the conversion between explicit knowledge and tacit knowledge. This paper will combine the knowledge into the SECI model to analyze.

\section{Development SECI Model in Teaching Process with Participation of Teachers and Students}

\subsection{Nonaka's SECI Model}

On the basis of further research the conversion between the explicit knowledge and tacit knowledge, Japanese scholars Nonaka's SECI model is currently the most influential model of knowledge transfer. He believes that knowledge creation is achieved through the process of transformation between the explicit knowledge and tacit knowledge with each other. Transformation of knowledge needed to complete by four processes. The four processes(Table 1) are:S(Socialization, from tacit to tacit), E(Externalization,from tacit to explicit),C(Combination, from explicit to explicit),I(Internalization, from explicit to tacit)[4].

Table 1. Transformation of Tacit and Explicit

\begin{tabular}{|c|c|c|c|}
\hline & $\begin{array}{c}\text { Tacit } \\
\text { knowledge }\end{array}$ & $\begin{array}{c}\text { Tacit } \\
\text { knowledge }\end{array}$ & \\
\hline Tacit knowledge & Socialization & Externalization & Explicit knowledge \\
\hline Tacit knowledge & Internalization & Combination & Explicit knowledge \\
\hline 4 & Explicit knowledge & Explicit knowledge & \\
\hline
\end{tabular}

Socialization,transformation from tacit to tacit, body of Knowledge-sharing share tacit knowledge by some sharing methods.

Externalization, transformation from tacit to explicit,the process of expression tacit knowledge into explicit concept. By Externalization transforming abstract tacit knowledge into explicit knowledge facilitates the 
exchange and understanding of knowledge. This process is the most important in the knowledge sharing process. Great capacity of tacit knowledge can be used and shared by more people only after it's explicitlized.

Combination, from explicit to explicit, refers to the transform from fragmented explicit knowledge into Systematic knowledge. Different body of knowledge-sharing classifies, synthesizes and analyzes all types of obtained information and knowledge,then makes them becom explicit knowledge easier to share.

Internalization, from explicit to tacit, Refers to closely integrate learning and practice, making explicit knowledge into the external part of personal knowledge, while it becomes the part of the assets of organization. Through "learning by doing", Some explicit knowledge would be turned into personal experience. Thus accumulation and innovation of knowledgecan be formed.

In a knowledge-sharing system, each of these four conversion mode is continuous and spiral. In the continuous transformation, expanding process of explicit knowledge and tacit knowledge, body of knowledge continues to acquire knowledge, accumulate knowledge and innovate knowledge, knowledge of the stock has been expanded, the quality of deepening. Similarly, in the teaching process with participation of teachers and students, The knowledge conversion models can contribute to knowledge acquisition, accumulation and innovation of Industrial and Commercial Management undergraduates, and further more facilitate the flexibility utility of exercise professional into practice.

\subsection{Expansion of SECI Model}

Based on Nonaka's SECI model, The paper established the expansion of SECI model with participation of teachers and undergraduates(Fig.1).The model includes eight knowledge transformation process. There are two knowledge layers of the model:undergraduate knowledge layer and teacher knowledge layer, The former is the transformation of knowledge among undergraduates, including four transformation processes, While there are also four transformation processes from teacher to undergraduate.

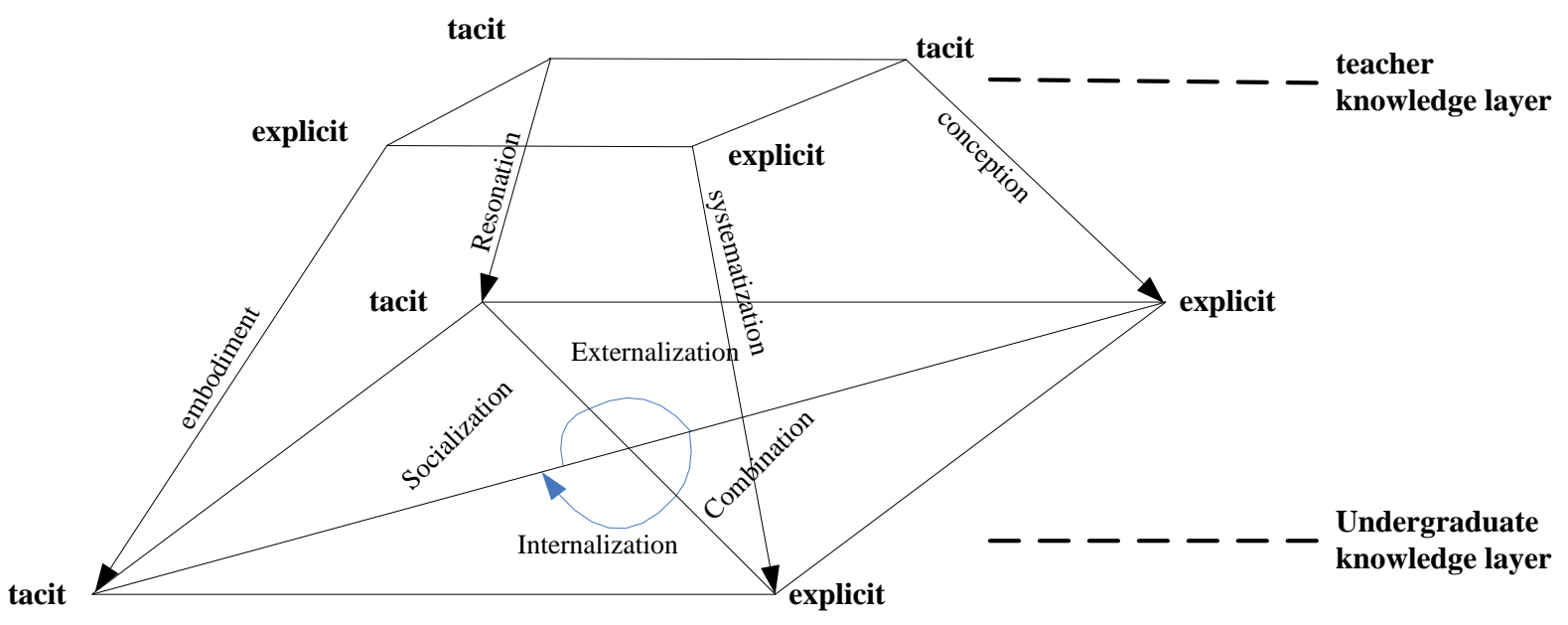

Fig. 1. Development SECI Model

Four knowledge transformation processes in the undergraduate level :

- Socialization in the undergraduate level, tacit knowledge of the undergraduate to tacit knowledge of the undergraduate. 
- Externalization in the undergraduate level, tacit knowledge of the undergraduate to explicit knowledge of the undergraduate.

- Combination in the undergraduate level, explicit knowledge of the undergraduate to explicit knowledge of the undergraduate.

- Internalization in the undergraduate level, tacit knowledge of the undergraduate to explicit knowledge of the undergraduate.

Four knowledge transformation processes from teacher to undergraduate:

- Resonation process, tacit knowledge of the teacher to tacit knowledge of the undergraduate.

- Conception process, tacit knowledge of the teacher to explicit knowledge of the undergraduate.

- Systematization process, explicit knowledge of the teacher to explicit knowledge of the undergraduate.

- Embodiment process, explicit knowledge of the teacher to tacit knowledge of the undergraduate.

Eight knowledge transformation processes in the expansion of the SECI model help to improve the professional knowledge of Industrial and Commercial Management undergraduates, and help students flexibly apply professional knowledge into practice, So this paper will combine the eight knowledge transformation processes to discuss teaching methods of Industrial and Commercial Management.

\section{Teaching Method Based on Expansion of SECI Model}

\subsection{Course of Social Practice}

Mainly through observation, imitation and other forms of personal practice tacit knowledge to tacit knowledge conversion process make tacit knowledge be passed , and make individual directly obtain new knowledge from others, that is to say through sharing of experiences to generate new tacit knowledge.

In teaching, in order to successfully share teachers' tacit knowledge to undergraduates and convert it into tacit knowledge of the undergraduates', social practice links need to be added. The way of adding social practice links are : 1)Teachers lead the undergraduates to participate in social activities of management; 2) Undergraduates participate in research projects and issues of teachers. Under the guidance of teachers, undergraduates master the tacit knowledge by Social Practice Management, thereby enhancing flexibility in the use of knowledge.

In order to promote convertion of tacit knowledge among undergraduates, in social practice management activity,teacher can divide the undergraduates into several groups to discuss each other and mutual guide .

\subsection{Case Teaching and other Vivid teaching methods}

Tacit knowledge to explicit knowledge conversion process is the explicit description of tacit knowledge, to be translated into the form of easy to understand for others, Analogy, metaphor, assumptions, listening and depth talks is a good way.

There are several teaching methods to facilitate convertion process from tacit knowledge of teachers into explicit knowledgeof the undergraduates,such as case teaching, appropriate outside visiting activity, report by enterprise managers and so on.

Knowledge externalization process among the undergraduates can be effectively realized by regularly organizing learning experience exchange, in exchange students will share their personal feelings and experiences with other students. Can also be case study in the classroom to the student, the case discussion between undergraduates, with complementary knowledge, information and emotional stimulation can encourage and create a good teaching results[5]. 


\subsection{Systematic Way of Teaching}

The conversion process of explicit knowledge to explicit knowledge is a process combining explicit knowledge into more complex, more systematic explicit knowledge. This is a process of knowledge diffusion, It often makes fragmentary explicit knowledge more systematic and complex,then integrate these fragmented knowledge and use professional language interpreting. Distributed document management, content management and data warehousing are effective tool of combinations of explicit knowledge.

Teachers teaching process is the typical process of convertion teachers' explicit knowledge into explicit knowledge of students.In the teaching process, teachers should pay attention to the language of expression, and teacher should be good at using some auxiliary teaching tools, such as multimedia, to facilitate the conversion of explicit knowledge of teachers to students explicit knowledge. In addition by online courses createed in the campus system, teachers can sort out course-related content into the systematic information and uploaded to the Internet to facilitate student access to information according to their needs.

In order to facilitate the conversion of explicit knowledge among students, teacher can give each group a large operating layout. Specific process is as follows:With the appropriate course teachers put forward several propositions related to course, and ask each group based on going through a larger number of literature to finish a short paper combining the proposition .

\subsection{Building Simulation Experiment}

Explicit knowledge to tacit knowledge is the conversion process of transfoming organization's explicit knowledge into tacit knowledge of organizational members.Group work, learning by doing and work training is the effective ways to achieve implicit of explicit knowledge.

So in the actual teaching process teacher can add some appropriate simulation experiments, such as ERP simulation[6], management decision simulation, simulation of financial decision-making, investment evaluation of simulation[7], computerized accounting, management information systems development and applications. This allows students to learn by doing to promote their explicit knowledge to tacit knowledge conversion process.

\section{Summarization}

Faced on human demand trends of 21st century knowledge economy and the international development of companies, Teaching Reform of Industrial and Commercial Management should be more adherence to the "Application + Innovation + Overall quality"teaching ideas to meet the overall goal of the development of the market economy, and with the combination of depth and breadth of expertise in Industrial and Commercial Management, reflecting the characteristics of undergraduate education, teaching reform should focus on cultivating the students skills of application, innovative thinking and enhance the overall quality of students.By analysisi on expansion of SECI model, the paper proposed some recommendations relevant to teaching means and methods of Industrial and Commercial Management, and expected to promote student flexible mastery of professional knowledge.

\section{Acknowledgements}

The authors appreciate the suggestions of associate professorYingwen Pan, and participants at Management School, Xi'an Polytechnic University, Xi'an, China. 


\section{References}

[1] Wang Kai, "Research in the Reform of Practice Education of Industrial and Commercial Management", Journal of Anhui University of Technology(Social Sciences), Vol . 21, No . 2,pp105-107, March , 2004 (in Chinese).

[2] Polanyi.M., The Study of Man. London:Routledge \& Kegan Paul,1957.12.

[3] Hu Zeping, Shi Qinfen, "An Analysis of Structure and Transforming Factors of Tacit Knowledge of Teachers in Universities", Journal of Science and Management Science,pp80-85, March , 2006 (in Chinese).

[4] Nonaka, I. \& Takeuchi, H. (1995), The Knowledge-Creating Company - How Japanese Companies create The Dynamics Of Innovation[M].Oxford University Press J. Clerk Maxwell, A Treatise on Electricity and Magnetism, 3rd ed., vol. 2. Oxford: Clarendon, 1892, pp.68-73.

[5] Jiang Yin, "Tacit knowledge of teachers and classroom education", Journal of Education Exploration, vol.147,pp90-92,NO.9,2003 (in Chinese).

[6] Sun Lijun, "A Study on Business Administration Education of University Students in China", Training and Research Journal of Hubei University of Education, Vol . 21 No. 6,pp65-67, Nov. 2004 (in Chinese).

[7] LIU Anmin , Luo Qiuming and LingWei, "On Specialiced Education Innovation of Industryand Commerce Administration Type", Journal of Jiangxi Normal University(Social Sciences), Vol . 37 No. 3, pp105-108, May 2004 (in Chinese). 